\title{
AS EMOÇÕES DOS CONSUMIDORES DA TERCEIRA IDADE NO PROCESSO DE ESCOLHA DE DESTINOS DE VIAGENS
}

\author{
THE EMOTIONS OF ELDERLY CONSUMERS IN THE \\ PROCESS OF CHOICE OF TRAVEL DESTINATIONS
}

Recebido 11/06/2012 Aceito 20/10/2012

Priscila Silva Esteves ${ }^{1}$ Luiz Antonio Slongo ${ }^{2}$

Cristiane Silva Esteves ${ }^{3}$

Renato Hübner Barcelos ${ }^{4}$

\section{RESUMO}

As emoções possuem grande importância para as decisões de compra, todavia, apenas há pouco se começou a estudá-las a partir de abordagens qualitativas. Nesse sentido, este estudo buscou analisá-las em um segmento ainda pouco explorado: os consumidores da terceira idade. Para isso, concentrou-se em um serviço pelo qual eles vêm demonstrando interesse - o turismo -, buscando analisar as emoções presentes no ato de escolha de destinos de viagens pela terceira idade e a sua influência em decisões de compras futuras, através da aplicação de entrevistas em profundidade, auxiliadas pela Photo Elicitation Technique (PET). Foi possível perceber que as emoções afetam a escolha por determinado destino de viagem, pois sensações vividas durante viagens anteriores ficam guardadas na memória e têm forte influência nos processos de decisão futuros. O trabalho ainda traz contribuições interessantes para futuras pesquisas ao investigar a ocorrência das emoções, não somente como um elemento apenas presente na decisão, como ocorre, normalmente, na maioria dos trabalhos sobre emoções, mas também como algo presente em três etapas do processo de consumo - antes, durante e depois da. Ao demonstrar que esta divisão é favorável ao melhor entendimento das emoções em todo o processo de escolha de destinos de viagem, abrem-se caminhos para outras pesquisas com distintas abordagens metodológicas.

Palavras-chave: Emoções, comportamento do consumidor, terceira idade, turismo.

\footnotetext{
${ }^{1}$ Possui graduação em Administração pela Universidade Federal do Rio Grande do Sul - UFRGS, especialização em Pedagogia Empresarial pela Escola Superior Aberta do Brasil, mestrado em Administração pela Universidade Federal do Rio Grande do Sul - UFRGS. Atualmente é doutoranda em Administração pela Universidade Federal do Rio Grande do Sul - UFRGS, professora do Instituto Federal de Educação, Ciência e Tecnologia do Rio Grande do Sul. Porto Alegre, Rio Grande do Sul, Brasil. E-mail: priesteves@gmail.com.

${ }^{2}$ Possui graduação em Administração pela Universidade Federal de Santa Maria - UFSM, mestrado em Administração pela Universidade Federal do Rio Grande do Sul - UFRGS e doutorado em Administração pela Universidade de São Paulo - USP. Atualmente é professor adjunto da Universidade Federal do Rio Grande do Sul - UFGRS. Porto Alegre, Rio Grande do Sul, Brasil. E-mail: laslongo@ea.ufrgs.br.

${ }^{3}$ Possui graduação em Psicologia pela Pontifícia Universidade Católica do Rio Grande do Sul - PUC/RS, especialização em Atendimento Clínico pela Universidade Federal do Rio Grande do Sul - UFRGS e mestrado em Psicologia pela Pontifícia Universidade Católica do Rio Grande do Sul - PUC/RS. Atualmente é doutoranda em Psicanálise pela Universidade Federal do Rio Grande do Sul UFRGS. Porto Alegre, Rio Grande do Sul, Brasil. E-mail: crissilvaesteves@gmail.com.

${ }^{4}$ Possui graduação em Engenharia Elétrica, graduação em Comunicação Social - Publicidade e Propaganda e mestrado em Administração pela Universidade Federal do Rio Grande do Sul - UFRGS. Atualmente é doutorando em Administração pela Universidade Federal do Rio Grande do Sul - UFGRS. Porto Alegre, Rio Grande do Sul, Brasil. E-mail: renatohubner@gmail.com.
} 


\section{ABSTRACT}

Emotions have great importance in purchasing decisions, however, only recently, researchers started to study them by qualitative approaches. In this context, this study sought to examine them in a still unexplored segment: elderly consumers. For this purpose, this research concentrated in a service for which they have shown a lot of interest - tourism - in order to analyze the emotions present in the choice of travel destinations and their influence on future purchasing decisions. That was done with the use of in-depth interviews aided by the Photo Elicitation Technique (PET). It was then observed that emotions affect the choice for a particular travel destination because the sensations experienced during previous trips are stored in memory and have a strong influence on future decision-making processes. This work also brings interesting contributions for future research because it investigated the occurrence of emotions in 3 separate stages of the consumption process - before, during and after the trip-and not only as just one element in this decision, as normally occurs in most researches about emotions. By demonstrating that this was a favorable decision to better understand the emotions throughout the entire purchase decision process, new paths are opened for further research with different methodological approaches.

Keywords: Emotions, consumer behavior, elderly consumers, tourism.

\section{INTRODUÇÃO}

O desenvolvimento científico e os avanços tecnológicos vêm permitindo um aumento considerável da longevidade da vida humana. Globalmente, a tendência é a existência de cada vez mais pessoas idosas, em função do controle da natalidade e da ampliação dos programas de saúde pública responsáveis pela redução das taxas de mortalidade tanto na infância quanto na velhice (LEAL; HAAS, 2006).

O percentual de idosos na distribuição etária dos países desenvolvidos e em desenvolvimento vem crescendo consideravelmente (IBGE, 2008). Nesse contexto, um aspecto inusitado vem sendo observado: os países em desenvolvimento estão apresentando índices de envelhecimento tão altos quanto os países desenvolvidos, chegando até mesmo a superá-los em alguns casos (UGALDE, 2006). Em 1990, apenas 26 nações possuíam populações idosas na marca dos milhões de pessoas; no ano 2000, 31 países atingiram este número e, possivelmente, daqui a 25 anos, haverá mais de 60 países com este contingente populacional (KINSELLA; VELKOFF, 2001). No Brasil, os efeitos do envelhecimento da população já começam a ser sentidos e terão um impacto ainda maior nos próximos anos (SLONGO et al, 2009).

Em função deste envelhecimento, a população de consumidores idosos está tornando-se bastante relevante para os profissionais de marketing, especialmente devido à disponibilidade de renda que grande parcela deste grupo possui para consumo. Koenigsberg (2004) afirma que há um enorme grupo de consumidores potenciais da terceira idade no mercado que dispõe de dinheiro para gastar, tempo para comprar e possui necessidade de adquirir novos produtos e serviços. Ainda segundo o autor, este grupo está crescendo em número e ainda não estabeleceu uma lealdade a lojas ou marcas de produtos. O segmento dos consumidores da terceira idade no Brasil representa um imenso potencial (FARIAS; SANTOS, 1998). Entretanto, somente um número reduzido de varejistas tem buscado este segmento: poucos vêm direcionando suas estratégias aos consumidores maduros.

Embora alguns setores da economia já tenham se voltado para o consumidor idoso, outros não perceberam que podem - e devem - desenvolver novos serviços e produtos, tanto na indústria como no varejo, que atendam às necessidades desta fatia de mercado ainda pouco explorada (ESTEVES; SLONGO, 2009). A população idosa possui, muitas vezes, necessidades e prioridades bastante diferentes das de jovens e adultos. Ao tentar compreender o comportamento deste público, é preciso ter consciência de que, embora os atributos e os benefícios funcionais dos produtos sejam importantes, estes representam apenas parte do que realmente os 
impulsiona a consumirem algum bem ou serviço (ZALTMAN, 2003). Como afirmam Sheth, Mittal e Newman (2001), necessidades e emoções estão intimamente relacionadas e são capazes de conduzir uma pessoa em direção aos seus objetivos. É indiscutivel que toda compra apresenta um aspecto racional de análise, síntese e comparação entre atributos do produto e outros aspectos; porém é inviável que as emoções fiquem excluídas desse processo (TREVISAN, 2004).

As emoções exercem grande importância no comportamento do consumidor (KEMP; BUI; CHAPA, 2012; MOWEN; MINOR, 2003) e, de acordo com Trevisan (2004), foi há pouco tempo efetivamente se começou a estudar a relevância e a influência das emoções no processo de consumo. Segundo a autora, este é um aspecto ainda pouco explorado não só no mundo empresarial, mas também no mundo acadêmico relacionado à área de marketing. Surpreendentemente, só agora isso está acontecendo, pois, em oposição à sua história em psicologia geral, que data de mais de 100 anos, a emoção é um tópico relativamente recente em comportamento do consumidor (OLIVER, 1997). No entanto, não há como eximir do contexto de consumo a presença das emoções (UGALDE, 2006).

É nesse contexto que este estudo se inseriu, investigando as emoções positivas e negativas no comportamento de consumo, mais especificamente dos consumidores pertencentes ao segmento da terceira idade. Ao mesmo tempo em que busca desvendar como o segmento da terceira idade se insere no contexto do consumo, a pesquisa também visa demonstrar a forma como as emoções interferem no processo decisório de compra no qual o idoso é sujeito.

Para isso, a investigação concentrou-se em um serviço pelo qual os idosos estão cada vez mais demonstrando interesse - o turismo -, buscando analisar as emoções presentes no ato de escolha de destinos de viagens pela terceira idade e a sua influência em decisões de compras futuras.

Para exposição do conteúdo deste trabalho, as suas partes estão estruturadas da seguinte maneira: primeiramente, é apresentada uma fundamentação teórica abordando os principais temas que embasaram a realização deste estudo; a seguir, o método é apresentado; e, após, segue-se a apresentação dos resultados. Por fim, são feitas as considerações finais, em que são apresentadas as implicações acadêmicas e gerenciais e as sugestões para futuras pesquisas.

\section{FUNDAMENTAÇÃO TEÓRICA}

Para respaldar teoricamente este estudo, foi feita uma revisão de literatura com foco em dois temas principais: o consumidor da terceira idade e as emoções.

\subsection{0 consumidor da terceira idade: alteração na estrutura etária brasileira}

A contínua queda da taxa de nascimentos e o aumento da expectativa de vida têm ampliado o número de adultos na população, fazendo com que os brasileiros na faixa de idade mais ativa (entre 15 e 64 anos) representem, atualmente, dois terços da população total do país. Essa transição demográfica que vem ocorrendo no Brasil, principalmente com relação ao envelhecimento da população, implica uma série de consequências sociais e culturais, além de uma série de necessidades e oportunidades de mercado para as quais muitas empresas ainda não estão preparadas (MOSCHIS, 2003). É importante ressaltar que a idade adotada pela Organização das Nações Unidas (ONU) como ponto de corte para definir alguém como idoso é de 65 anos para países desenvolvidos e de 60 para países em desenvolvimento. Já a Organização Mundial da Saúde (OMS) define o estágio inicial do envelhecimento como sendo a partir de 60 anos de modo geral, o que se passou a determinar de terceira idade (UGALDE, 2006).

Essa alteração na estrutura etária do país pode também ser observada na Figura 1, ela- 
borada por Esteves e Slongo (2009) com base nas projeções populacionais do Instituto Brasileiro de Geografia e Estatística (IBGE), de 2008. Nela são apresentadas as pirâmides populacionais de 1980, juntamente com as projeções elaboradas pelo IBGE para 2015 e 2050.

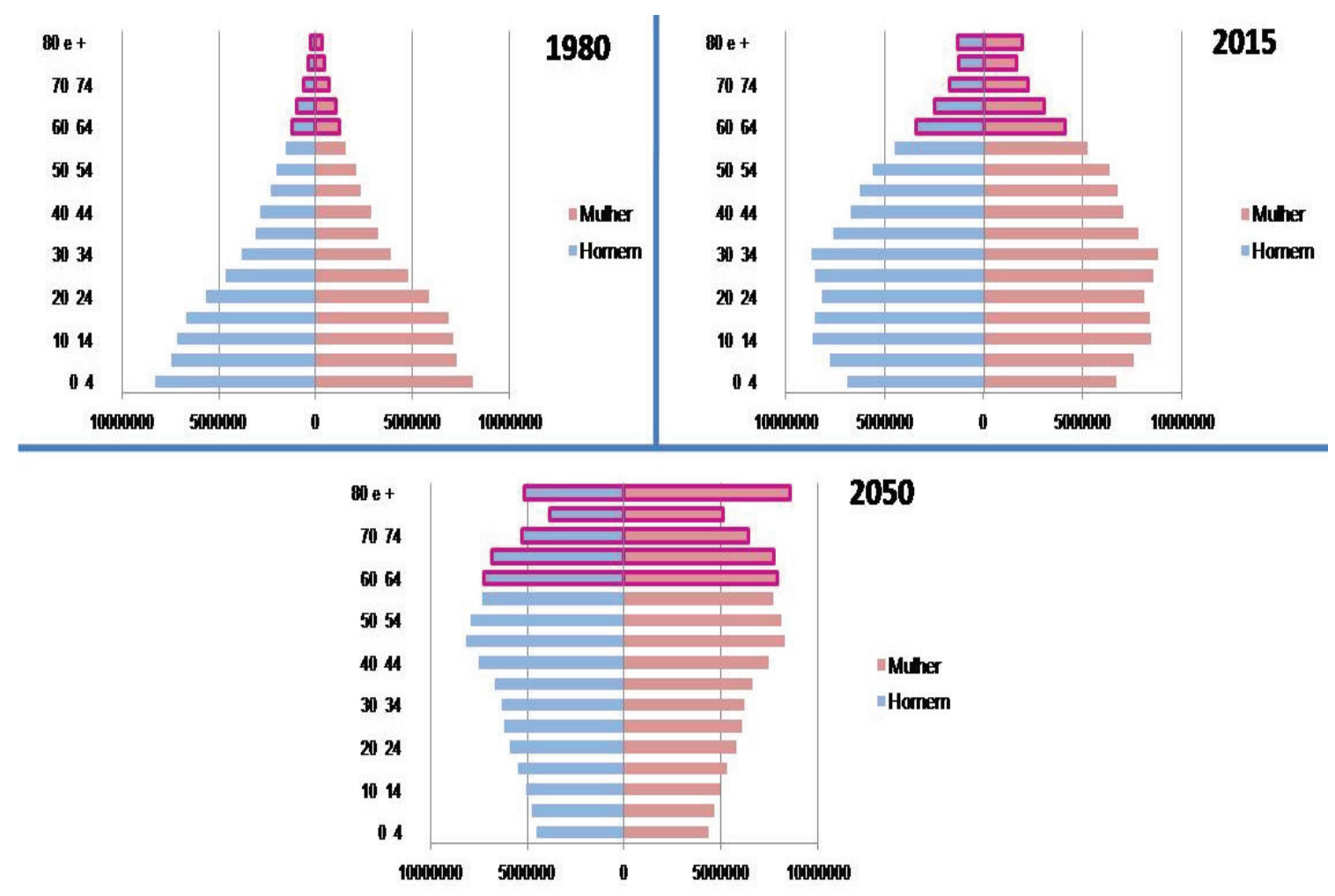

Figura 1: Pirâmides etárias brasileiras.

Fonte: Baseada em dados do IBGE (2008).

É possível perceber que as projeções indicam um estreitamento na base da pirâmide, bem como um crescimento no topo. Isso assinala a desestabilização da estrutura etária do país e aponta para o envelhecimento da população. Em 1980, os idosos totalizavam 6,2\% da população total do país, em 2015, esse número crescerá para 11,6\%, chegando a um total de $29,8 \%$ em 2050 (IBGE, 2008). De acordo com o IBGE (2008), em 1980, havia um total de 7.197.904 idosos, e a expectativa de vida da população brasileira era de 62,60 anos $(65,69$ para mulheres e 59,62 para homens). As projeções indicam que, em 2015, o total de idosos aumentará para 23.230.287 e, em 2050, para 64.050.980, dos quais 160.000 terão idade acima de 100 anos. Em 2012, a expectativa de vida dos brasileiros era de73,95 anos (77,79 para mulheres e 70,25 para homens). A tendência é que esta expectativa continue a crescer e passe para uma média de 81,29 anos em 2050, (84,54 para mulheres e 78,16 para homens) (IBGE, 2008). Segundo Berquo e Cavenaghi (2006), outro fator que contribui para a inversão da pirâmide populacional é a redução da média brasileira de filhos por mulher que, em 1970, era de 5,8 e, em 2004, baixou para 2,1 filhos por mulher. Esse índice chega a 1,4 no caso das mulheres com mais de doze anos de instrução.

$O$ envelhecimento da população brasileira vem revelando um novo nicho de mercado consumidor, com valores, comportamentos, estilos de vida e necessidades específicas. Para Ballstaedt (2007, p. 9), "foi-se o tempo em que ser idoso era sinônimo de cadeira de balanço, cestinha de tricô, mau humor e reumatismo". Hoje, com o aumento da expectativa de vida, a imagem de idoso está também vinculada a cosméticos que rejuvenescem, perfumam e embelezam, vitami- 
nas fortificantes, viagens ao exterior, passeios e até faculdades.

Uma vez que a paternidade se estende por muitos anos, é natural achar que a póspaternidade, quando todos os filhos já saíram de casa, seja traumática para alguns pais [...] Esse tão falado estágio do ninho vazio significa para muitos pais quase um "renascer", um tempo de fazer todas as coisas que não puderam enquanto os filhos estavam em casa [...] É tempo de viajar, se divertir, comprar móveis novos para redecorar a casa, ou vender a casa para comprar uma casa nova [...]. Hoje esses "sem filhos" têm mais tempo livre. Viajam com mais frequência, têm férias prolongadas e tendem a comprar uma segunda casa (SCHIFFMAN; KANUK, 2000, p. 258).

\subsubsection{Lazer e produtos para a terceira idade}

Dentro deste contexto de mudança na estrutura etária brasileira, alguns setores que vêm despertando para a demanda dos consumidores da terceira idade são o de turismo e lazer, nos quais é crescente o número de agências de viagens com pacotes idealizados exclusivamente para o público idoso. Dessa maneira, o setor do turismo vem se tornando uma das principais atividades econômicas tanto nos países desenvolvidos quanto nos em desenvolvimento (AZEVEDO et al., 2012) Em estudo realizado sobre o comportamento dos consumidores de terceira idade em relação ao entretenimento e ao lazer, Ladeira, Guedes e Bruni (2003) afirmam que este grupo possui tempo disponível e recursos para viajar, isto é, para consumir produtos e serviços de turismo, caracterizando-se, assim, em um segmento atrativo para esta indústria.

De acordo com Ballstaedt (2007), o lazer é o segmento da terceira idade que mais cresce, tornando a diversão um bom negócio. Os especialistas são unânimes ao afirmar que o turismo é a melhor forma de socialização e formação de vínculos pessoais, dois itens essenciais nesta fase da vida. Em função disso, cresce o número de empresas especializadas em levar grupos de terceira idade para conhecer diferentes localidades do Brasil e do exterior.

Segundo matéria na revista Exame (2008), com base na percepção da força da terceira idade como consumidora, a CVC (maior operadora de turismo do Brasil) vem fazendo adaptações na prestação de seus serviços para atender a esse público emergente. Durante o ano, 40\% do 1,5 milhão de consumidores que procuraram a agência para viajar tinham mais de 50 anos. Nos cruzeiros marítimos, com roteiros que passam de 18 dias, a faixa etária média foi acima dos 60 anos. Com isso, as agências têm preparado a tripulação dos navios para lidar com esse público, dando-Ihes orientações que vão desde como administrar injeções de insulina em passageiros diabéticos até nunca se esquecer de oferecer cobertores extras nos dias de frio. A expectativa é de que os idosos do futuro, além de mais numerosos devido ao aumento da expectativa de vida, tenham mais dinheiro (EXAME, 2008).

Com o aumento do número de viagens feitas pela terceira idade, crescem as oportunidades de negócio para as agências de viagens. Estas precisam ter consciência de que o consumidor idoso possui necessidades e desejos especiais e pode, se bem atendido, trazer retornos financeiros significativos. Fleischer e Seiler (2002) explicam que os turistas maduros tendem a ser considerados como um grupo homogêneo e, embora haja uma tendência de generalizar o comportamento dos idosos, é preciso observar que existe grande diversidade entre eles, tanto em termos de atitudes, como de comportamentos. Grande parte dessa população não se encaixa nos estereótipos de "velho", aquele que é fraco, pobre e sem maiores interesses e ambições na vida (SHERMAN; SCHIFFMAN, 1991). 


\subsubsection{Estudos sobre o mercado da terceira idade}

O estudo do mercado da terceira idade e dos esforços de marketing realizados para abordar as necessidades do idoso pode ser caracterizado em três etapas, segundo Moschis (2003): uma anterior à década de 80 , outra durante a década de 80 e a seguinte a partir dos anos 90 .

Antes da década de 80 - negligência total: Até então, o foco das companhias era os consumidores jovens, normalmente aqueles com até 50 anos. $O$ consumidor mais idoso era visto como parte de um segmento desprivilegiado da população, com limitados recursos econômicos e de pouca importância. Como resultado, a maioria dos esforços de marketing para a terceira idade limitava-se a ofertas que seguiam essa percepção, como descontos para idosos.

Anos 80 - marketing de tentativa e erro: Bartos (1980) considera o segmento de mercado composto por aqueles com mais de 50 anos como maduro, constituído por um grande número de pessoas com diferentes estilos de vida e poder de compra. Os profissionais de marketing começaram a se interessar por esse mercado, porém ainda havia pouca informação confiável para tomadas de decisão eficientes. Assim, muitas ações das agências eram desenvolvidas baseadas em estereótipos da terceira idade, e muitas propagandas da época retratavam os idosos como um grupo homogêneo de pessoas rabugentas, isoladas e de pouca saúde, que gostavam de estar com outras pessoas idosas e de comprar produtos projetados exclusivamente para eles.

Anos 90 até hoje - maior empenho e cautela: Um número crescente de companhias passou a reconhecer o mercado da terceira idade e a desenvolver programas de marketing para atingi-lo eficientemente. Além disso, profissionais de marketing passaram a ser mais cautelosos no desenvolvimento de produtos e de mensagens para atingir esse mercado.

Segundo Nam et al. (2007), a falta de atenção para com o mercado da terceira idade pode ser atribuída a fatores como: a tendência de continuar com estratégias promocionais de décadas anteriores (quando os jovens consumidores eram maioria); os estereótipos negativos associados às pessoas mais velhas, o medo de alguns profissionais de marketing de que seus produtos sejam associados à senilidade, deficiência e baixa atratividade ou, ainda, o pensamento de que buscar oportunidades junto à terceira idade seria adentrar em um "beco sem saída". Entretanto, de acordo com Gomes et al. (2012), para construir um relacionamento de longo prazo, é preciso que as necessidades dos clientes sejam conhecidas para, dessa maneira, encurtar os laços de relacionamento e viabilizar a fidelização. Diante disso, é necessário que as empresas fiquem atentas às necessidades do público da terceira idade, que vem se tornando um mercado muito promissor.

\subsection{As emoções}

Apesar do grande número de estudos que desenvolveram conhecimento sobre o tema, é difícil encontrar na literatura uma definição única de emoção (LARAN, 2003; SHETH; MITTAL; NEWMANN, 2001). Não é fácil definir emoção, principalmente quando se está à procura de um conceito único para isto (ARRUDA, 2002). Mesmo assim, diversos autores buscaram formas de definir este termo.

\subsubsection{Definições de emoções}

Segundo Sheth, Mittal e Newman (2001), as emoções são a consciência da ocorrência de alguma excitação fisiológica seguida por uma resposta comportamental, juntamente com a avaliação do significado de ambas. Essa definição implica que as emoções têm três componen- 
tes: fisiológico, comportamental e cognitivo. Já para Bagozzi, Gopinath e Nyer (1999), emoção significa um estado mental de prontidão que surge a partir de avaliações cognitivas de eventos ou pensamentos. As emoções têm um tom fenomenológico, são acompanhadas por processos fisiológicos e são, muitas vezes, expressas fisicamente (ex: nos gestos, postura, expressões faciais).

Complementando estas ideias, Schiffman e Kanuk (2000) afirmam que não há como separar as emoções das pessoas em qualquer processo de compra de qualquer produto ou serviço. Sheth (2001) acrescenta ainda que:

As necessidades e as emoções são intimamente relacionadas. Da mesma forma que as necessidades, as emoções são também capazes de energizar a pessoa na direção de objetos-meta apropriados. [...] A maioria do consumo ou o uso de produtos é conduzida pela emoção e está imersa nela (SHETH, 2001, p. 147).

Nesta mesma perspectiva, Bagozzi, Gopinath e Nyer (1999) afirmam que as emoções são centrais para as ações dos consumidores, surgindo em resposta a uma avaliação (um julgamento, uma interpretação) que as pessoas fazem de algo relevante (incidente ou episódio que acontece com o indivíduo, algo não planejado) para o seu bem-estar. Dessa forma, a emoção é uma reação afetiva para a percepção que as pessoas têm das situações (RICHINS, 1997). O que produz uma emoção é uma avaliação psicológica única da pessoa que está avaliando o evento; diferentes indivíduos podem ter reações diversas ou nenhuma reação quando expostos à mesma situação (BAGOZZI; GOPINATH; NYER, 1999).

\subsubsection{A importância do estudo das emoções para o comportamento do consumidor}

Embora os atributos e os benefícios funcionais dos produtos sejam importantes em um processo de decisão, representam apenas uma parte do que realmente impulsiona os consumidores (ZALTMAN, 2003). Diversos fatores ambientais e individuais influenciam também na decisão de compra dos consumidores, tais como: os valores; as características demográficas; as motivações; a classe social; a cultura; a influência dos amigos e da família (HSIEN et al., 2011). Além disso, as decisões de compra também são motivadas por emoções e, assim sendo, não há como separar o lado emocional deste processo. Integrando-se ao modelo de tomada de decisões racionais, os aspectos emocionais são, de acordo com Costa e Farias (2004), relevantes influenciadores do processo de decisão de compras (KEMP; KOOP, 2011). Fatores afetivos desempenham importante papel no processo de decisão de compra, bem como no desenvolvimento e na manutenção da preferência dos consumidores por determinados produtos, sejam eles bens ou serviços (SHIV; FEDORIKHIN, 1999).

A partir desta constatação, pesquisadores de marketing passaram a considerar também o estudo das emoções e suas implicações nas situações de compra e consumo (HOLBROOK; HIRSCHMAN, 1982). De acordo com Larán (2003), a Teoria Cognitiva das Emoções ganhou corpo na psicologia a partir do início da década de 60 e é a mais utilizada nos estudos de marketing. Espinoza (2004) argumenta que a existência de trabalhos cuja linha segue uma abordagem cognitivo-afetiva indica os rumos da evolução da disciplina.

Segundo Sternberg (2000), a Psicologia Cognitiva estuda o modo como as pessoas percebem, aprendem, recordam a informação, bem como a forma que pensam sobre ela. A Teoria Cognitiva das Emoções propõe que as emoções são consequências de avaliações que as pessoas fazem em relação à significância de determinado evento para o seu bem-estar (KUMAR; OLIVER, 1997). 
De acordo com Peter e Olson (1994), a cognição está relacionada com os processos mentais, pensamentos e significados produzidos pelo sistema cognitivo. As principais funções deste sistema são interpretar os aspectos do ambiente e processar as informações. Um certo grau de independência entre o sistema afetivo e o cognitivo é plausível, entretanto não se pode negar a sua interconexão e influência mútua. Assim sendo, o estado afetivo é capaz de ativar a percepção do consumidor a respeito de um produto, já que as reações afetivas dos consumidores influenciariam as suas cognições durante o processo decisório.

Lazarus (1991) foi um dos pesquisadores que estudou profundamente o papel da cognição nas emoções, demonstrando em suas pesquisas a forte associação entre os eventos e as reações advindas da avaliação destes. Este autor analisou as emoções como um sistema cognitivo, partindo da concepção de que elas são uma forma de captar o mundo, funcionando como mapas mentais a respeito de algumas crenças dos indivíduos. De acordo com ele, é isto que faz com que as emoções sejam cognitivas, e é por essa razão que a avaliação cognitiva é incluída como uma característica fundamental da resposta emocional. A partir disso, autores como Westbrook e Oliver (1991) afirmam que as emoções nas experiências de consumo são prognósticos significativos da satisfação, o que os levou a propor escalas de mensuração dos estados emocionais ativados nestas experiências.

Carrol Izard (1977), por meio da Differencial Emotion Scale (DES), examinou emoções através das respostas dos músculos faciais associadas à emoção, propondo a existência de dez emoções fundamentais. Robert Plutchik (1980), por sua vez, usou uma perspectiva evolucionária para identificar oito emoções primárias (RICHINS, 1997). As abordagens de Izard (1977) e Plutchik (1980) partem do princípio de que existem emoções básicas que determinam todas as outras (LARÁN, 2003). Mehrabian e Russell (1974) desenvolveram a escala PAD (Pleasure-Arousal-Dominance), apresentando pares de adjetivos, tais como: calmo/excitado, feliz/infeliz, influenciado/ influenciador, entre outros. Há, ainda, a Escala PANAS (Positive Affect Negative Affect Scales), desenvolvida por Watson, Clark e Tellegen (1988), que divide as emoções em afeto positivo e afeto negativo (dimensões distintas e ortogonais) e a Escala CES (Consumption Emotions Set), desenvolvida por Richins (1997), que é um conjunto de descritores representando a série de emoções que os consumidores mais frequentemente experimentam em processos de compra de diferentes tipos de produtos.

Estas escalas foram criadas como tentativas de identificar e mensurar emoções, entretanto ainda se mostram incompletas por não serem capazes de considerar a complexidade e a variedade de emoções possíveis de serem vivenciadas (RICHINS, 1997). Apesar disso, os princípios destas escalas podem ser empregados de forma alternativa em técnicas qualitativas, servindo como categorias iniciais para a construção dos instrumentos de coleta de dados e para a realização das análises. Como será discutido a seguir, essa estratégia possibilita um exame mais amplo das emoções envolvidas no consumo.

\section{METODOLOGIA}

Tendo em vista os objetivos deste estudo, o método escolhido foi do tipo exploratório, através de pesquisa de natureza qualitativa. Apesar de existirem diversas escalas que tratam de emoções, há limitações nelas, uma vez que emoções importantes, tais como o amor, não são consideradas (RICHINS, 1997). Desse modo, a escolha deste método justifica-se tanto por isso quanto pelo fato de que, conforme Goebert (2003), as pesquisas qualitativas, quando bem conduzidas, estimulam os consumidores a revelar seus processos de pensamento e detectam sua 
relação emocional com marcas e produtos. Além disso, acredita-se que "as emoções são, por definição, inconscientes" (ZALTMAN, 2003, p. 37) e, por consequência, perder-se-ia muito ao pesquisar emoções através de métodos estritamente quantitativos.

A incorporação dos métodos qualitativos à pesquisa do consumidor responde à necessidade de utilização de metodologias que permitam interações e construções acerca de um tema tão diverso. Esses métodos produzem dados de maior validade do que questionários, devido à interação flexível entre pesquisador e pesquisado, que favorece o surgimento de elementos novos e não esperados a priori e o entendimento de aspectos ambíguos não capturados por instrumentos que padronizam os dados (GOLDMAN; MCDONALD, 1987).

Nesse sentido, Hirschman e Holbrook (1992) observaram que a dominância de métodos positivistas, neopositivistas ou quase-positivistas de investigação na pesquisa do consumidor, com a consequente ênfase em técnicas quantitativas, representa um importante desafio dos pesquisadores da área. Em razão disso, é fundamental que sejam buscados métodos alternativos que agreguem informações importantes para esta área do conhecimento. A crítica a essa dominância tem sido motivadora de diversos artigos e livros publicados nos últimos anos (ROSSI; HOR-MEYLL, 2001). Tendo como base estas constatações, a escolha dos métodos de pesquisa deu-se pela técnica qualitativa de entrevistas em profundidade, auxiliadas por Photo Elicitation Technique (PET), com ênfase nas suas características e aplicações.

Zaltman e Coulter (1995) abordam a importância de se utilizar técnicas alternativas na pesquisa sobre o consumidor, tornando-a mais interativa, a fim de engajar mais o entrevistado no processo. Segundo estes autores, devido à crescente escassez de tempo, é cada vez mais difícil garantir que o entrevistado esteja focado e interessado na pesquisa. É neste contexto que surge a PET, método de pesquisa que utiliza figuras para guiar entrevistas e estimular a discussão durante estas (KLITZING, 2004). De acordo com Harper (2002), a PET consiste em um método qualitativo e de natureza pós-moderna, que objetiva a exploração de sentimentos, pensamentos e ideias, através do uso de imagens.

Neste estudo, foi solicitado que os entrevistados separassem previamente algumas fotos de viagens que fizeram para serem utilizadas na entrevista, a fim de que se recordassem de momentos vivenciados nelas. Além disso, a entrevistadora separou previamente 27 imagens (de situações de viagens, expressões faciais e paisagens) para serem apresentadas aos entrevistados, solicitando-lhes que escolhessem algumas com as quais mais se identificassem (ou que os fizessem recordar de algum sentimento similar vivido em algum momento de suas viagens) e, logo após, relatassem o que lhes veio à mente.

Além da importância já mencionada do uso de múltiplas técnicas, Foxall (2001), Zaltman e Coulter (1995) identificaram a necessidade de abordagens multidisciplinares nas pesquisas acerca do comportamento do consumidor. Zaltman (2000) ainda incitou os pesquisadores de comportamento do consumidor a saírem do falso conforto oferecido pela conviç̧ão de que a disciplina é aberta o suficiente para permitir o trabalho em outros campos. Tendo isso em vista, buscou-se o assessoramento de uma profissional de Psicologia, visando à interdisciplinaridade dentro da pesquisa do comportamento do consumidor. A psicóloga acompanhou as etapas de elaboração e validação do roteiro de entrevistas, bem como a análise de dados, o que contribuiu para desvendar as emoções sentidas pelos entrevistados, uma vez que o assunto emoções é muito estudado por pesquisadores desta área do conhecimento.

Primeiramente, foram entrevistados três profissionais que trabalham com vendas de pacotes de viagens para coletar informações sobre o mercado de turismo. A partir destas entrevistas, foi elaborada uma primeira versão do roteiro de entrevistas, considerando também, 
como categorias de questionamento, os itens das escalas de emoções mencionadas no capítulo anterior. Este roteiro foi testado com duas pessoas com mais de 60 anos e alguns ajustes foram, então, feitos para se chegar à versão final. As entrevistas foram conduzidas nos locais escolhidos pelos próprios participantes. Tiveram duração média de 55 minutos, totalizando 378 páginas de transcrição.

Por fim, foi feita a análise de conteúdo dos dados, conforme a proposta de Bardin (2008), que se refere à decomposição do discurso e à identificação de unidades de análise ou grupos de representações para uma categorização dos fenômenos. A partir daí, se tornou possível reconstruir significados que apresentassem uma compreensão mais aprofundada da interpretação da realidade a partir das percepções dos entrevistados (GODOY, 1995). As categorias iniciais da análise aproveitaram os itens da escala CES (Consumption Emotions Set) de Richins (1997), considerada mais relevante por cobrir a maioria das reações emocionais encontradas no consumo (BAGOZZI; GOPINATH; NYER, 1999). O software utilizado para a análise e categorização dos dados coletados foi o NVivo v. 8.

Para a análise dos dados, a fim de conseguir maior confiabilidade, utilizou-se a técnica denominada triangulação. Esta, segundo Minayo (1993), consiste na combinação e no cruzamento de múltiplos pontos de vista através de múltiplos informantes, de múltiplas técnicas de coletas de dados e do trabalho conjunto de vários pesquisadores. No presente trabalho, a psicóloga e os autores deste estudo realizaram suas análises do conteúdo das entrevistas de forma separada e independente. Após esta etapa, foram feitas diversas reuniões, nas quais os conteúdos de cada uma das entrevistas foram debatidos, buscando-se pontos comuns e pontos divergentes, a partir dos quais foram estabelecidas as categorias finais de análise.

\subsection{Caracterização dos respondentes}

Os métodos de pesquisa previamente explanados foram aplicados em um grupo selecionado por julgamento, composto por pessoas de 60 anos ou mais, que gostam e tenham o hábito de viajar. O número total de entrevistas foi determinado pelo critério de saturação de dados, isto é, pelo ponto em que há grande incidência de repetição e em que a contribuição marginal de novos entrevistados passa a ser muito pequena para o desenvolvimento da pesquisa (FLICK, 2004). Assim, foram entrevistadas 20 pessoas (15 mulheres e cinco homens) residentes em Porto Alegre, com idade entre 61 e 87 anos (média de 69,2 anos), no primeiro semestre de 2010. Destas, 14 eram aposentadas (em média, há 14,5 anos), quatro encontravam-se ativos e duas sempre atuaram como donas de casa.

\section{ANÁLISE DOS RESULTADOS}

As categorias finais da análise foram desenvolvidas e agrupadas em três áreas centrais: emoções vivenciadas antes da viagem, emoções vivenciadas durante a viagem e emoções vivenciadas depois da viagem (Quadro 1). Neste capítulo, primeiramente são discutidos os resultados inseridos nestes temas centrais e, a seguir, os resultados obtidos através da Photo Elicitation Technique (PET).

\section{Categoria de análise $\quad$ Emoções}

Emoções vivenciadas Emoções positivas: entusiasmo, alegria e expectativa. antes da viagem Emoções negativas: ansiedade (associada a problemas vivenciados nos aeroportos). 
Categoria de análise

Emoções vivenciadas durante a viagem

Emoções vivenciadas depois da viagem

Quadro 1 - Categorias finais de análise e emoções vivenciadas: processo decisório de escolha de destinos de viagem. Fonte: Dados da pesquisa.

\subsection{Emoções vivenciadas antes da viagem}

A tomada de decisão dos consumidores envolve, concomitantemente, a ação da razão e da emoção; e, por mais que ambas pareçam excludentes, as emoções contribuem como elementos essenciais do bom processo decisório (LEE et al., 2011; DAMÁSIO, 1994). Conforme pôde ser observado a partir das entrevistas, as emoções (tanto as positivas quanto as negativas) estão presentes durante todo o processo de escolha de um destino de viagem.

Entre as diversas emoções expressadas pelos entrevistados nos momentos que antecedem a escolha de um destino e as que ocorrem no período entre a escolha e a realização da viagem, podem ser destacadas: entusiasmo, ansiedade, alegria e expectativa.

Ai, eu fico tão ansiosa, menina, não vejo a hora de chegar. Não vejo a hora de ir [...] e eu adoro, chegar no aeroporto, demora para despachar as malas, não tô nem aí, fico lá esperando o tempo que for (Entrevistada 19/62 anos).

A viagem, eu sempre penso assim, é como a propaganda do Whisky: é bom antes, durante e depois. É bem assim... O antes é gostoso, é onde entra o teu sonho, aquelas emoç̃es "eu vou ver isso, vou ver aquilo", ai que coisa boa! [...] Aí a tua mente começa a trabalhar e imaginar o que tu vais fazer (Entrevistada 6/77 anos).

Eu curto muito a viagem antes da viagem. [...] vou te dizer, às vezes eu curto mais antes, do que depois. Curto tanto antes, quanto durante (Entrevistado 17/64 anos).

Para Zaltman (2003), as emoções são, por definição, inconscientes. Portanto, como comentam Espinoza e Nique (2003):

[...] não depende apenas da vontade do indivíduo em sentir ou não alguma emoção. Emoções parecem simplesmente "acontecer" e parecem contornar o sistema racional e o livre-arbítrio. Embora a expressão de uma emoção possa ser suprimida e controlada, o sentimento permanecerá (ESPINOZA; NIQUE, 2003, p. 3).

Essa característica das emoções pôde ser observada em relatos de algumas entrevistas, nos quais estas afirmaram ter tentado, sem êxito, controlar suas emoções, principalmente quando estavam junto umas das outras. $O$ trecho a seguir exemplifica essa situação, na qual uma das entrevistadas estava narrando alguns momentos que antecederam uma viagem que fez.

Eu chorei sem poder, "ai [...] eu vou ficar longe, dois meses, ai meu Deus do céu, o que vai ser de mim?" [me disseram] "ai, Cissa, não chora". Mas não adianta dizer "não chora", porque a emoção vem, né?! Não adianta tu dizer, a lágrima vem mesmo (Entrevistada 12/79 anos). 


\subsection{Emoções vivenciadas durante a viagem}

As emoções vivenciadas durante as viagens foram as que mais se destacaram durante as entrevistas. Por diversas vezes, os entrevistados contaram fatos ocorridos durante suas viagens, descrevendo emoções sentidas sem, muitas vezes, saber classificá-las ou, até mesmo, justificar o porquê de tê-las sentido. Segundo Trevisan (2004), ao analisar as percepções sobre emoções e a sua relação com o consumo, percebe-se que as emoções são inerentes ao cotidiano de qualquer consumidor, seja ele homem ou mulher, velho ou jovem, rico ou pobre, independentemente do que se denomine como emoção.

Essas emoções, assim, tem coisa que é difícil tu descreveres, que tu te enche a tua alma de ver aquilo (Entrevistada 6/77 anos).

Dentre as diversas emoções identificadas nos depoimentos das pessoas, foram identificadas tanto emoções positivas quanto negativas. No primeiro grupo, destacam-se: alegria, surpresa, liberdade e encantamento. Em algumas situações narradas, a realização de determinada viagem correspondia à realização de um sonho. Assim, a chegada ao destino aflorou sensações e emoções positivas nos idosos.

Ah, uma emoção muito grande, porque a gente aqueles lugares santos, aqueles lugares que a gente já conhecia da Bíblia, né?! Então isso aí mexeu muito com a emoção. Valeu a pena (Entrevistada 11/87 anos).

Essa vez eu fui para Nova lorque porque eu não conhecia neve. Sabe aquele pessoal de interior que nunca viu neve? E eu vi bastante, fiquei feliz da vida, foi uma viagem maravilhosa [...] achei a coisa mais linda do mundo. Quis ficar embaixo da neve para poder sentir, ai que bobeira, mas eu achei lindo aqueles flocos de neve caindo, parece algodão, as árvores tudo branquinha de neve. Ai, eu fiquei apaixonada, isso aí foi uma coisa que me deixou bem feliz (Entrevistada 19/62 anos).

Dentre as principais emoções negativas sentidas durante as viagens, foram identificadas: insatisfação, descontentamento, vergonha, frustração e medo.

As [emoções] negativas ocorreram antes de 1989 quando caiu o muro dos países socialistas, eu visitei Tchecoslováquia, tive na lugoslávia, Polônia, Alemanha Oriental, na época do muro ainda, então isso foram impressões negativas, porque tu entravas num país preto e branco, cinza, sem atração, com risco altíssimo de não te deixarem entrar nas fronteiras, esvaziar a bolsa, trocar o dinheiro ocidental por oriental (Entrevistado 18/62 anos).

Cairo, a parte histórica de Cairo eu já conhecia, mas aí tem umas emoções negativas ao mesmo tempo... Pertinho das pirâmides tem um avanço muito grande de casas, umas casas feias, velhas (Entrevistada 4/74 anos).

Damásio (1999) propõe que existe algo acentuadamente característico no modo como as emoções vinculam-se a ideias, valores, princípios e juízos complexos que só os seres humanos podem ter. Sem exceção, homens e mulheres, de todas as idades, de todas as culturas e de todos os níveis de educação têm emoções, são cuidadosos com as emoções dos outros e governam suas vidas perseguindo uma emoção - a felicidade - e evitando emoções desagradáveis - a tristeza, a frustração, o medo etc. Isso pôde ser observado nos depoimentos, principalmente naqueles em que os entrevistados afirmavam que desistiam de ir a determinados destinos ou de utilizar algum meio de transporte devido ao medo que sentiam. 
Fiquei empolgadíssima pra ir pros Estados Unidos. Só que a gente tem um pouco ainda de medo, né, um pouco de medo dessas coisas, desses atentados. [...] tenho muito medo, de ir lá pro Líbano, pra Irã, Iraque, essas coisas, pra esses países que eu acho que é muito perigoso, né, acho que é muito perigoso (Entrevistada 10/61 anos).

É, eu evito, assim, muitas vezes [fazer cruzeiros]. Por exemplo, na agência, a minha sócia diz: "ai, tu não imagina, que coisa maravilhosa" ela quer me convencer de fazer um cruzeiro, atravessar o oceano Atlântico e eu não tenho coragem. Não tenho coragem... 0 oceano atlântico, tu já imaginaste no meio do oceano atlântico? Tá longe de tudo que é lado, o que a gente vai fazer? Eu tenho medo! (Entrevistada 6/77 anos).

É interessante observar, porém, que os entrevistados tiveram facilidade de narrar situações nas quais sentiram emoções positivas, o que já não ocorreu quando foi solicitado que fizessem o mesmo em relação a alguma emoção negativa.

De ruim assim não lembro. Ai, graças a Deus eu acho que o ser humano foi tão bem feito que a gente, as coisas ruins esquece muito mais. Aquilo que é ruim, deixa para lá e pronto! (Entrevistada 1, 64 anos).

Não tô lembrada agora. Acho que a gente deleta as coisas ruins, porque são tantas coisas boas que a gente acaba vendo, lugares gostosos (Entrevistada 2/70 anos).

\subsection{Emoções vivenciadas depois da viagem}

As emoções mostraram-se ainda bastante presentes mesmo após o final das viagens realizadas pelos entrevistados. Para eles, o "voltar para casa" é, também, um momento muito importante e carregado de emoções, tanto positivas quanto negativas. As emoções positivas estão associadas à conquista dos objetivos e envolvem comportamento positivo, atração ou aproximação. As negativas são resultantes de eventuais falhas ou problemas e envolvem fuga, recuo ou comportamento negativo. Segundo Espinoza e Nique (2003).

Aí depois de vinte dias com aquele "daradaradara" no teu ouvido, tu chegares em São Paulo, saber que vais chegar em Porto Alegre, é só felicidade. [..] é muito bom viajar, tudo é muito bom, tudo é muito lindo [...] mas tu chegares em casa é a melhor parte da viagem. Para qualquer lugar que tu fores... o chegar em casa não existe (Entrevistada 1/64 anos).

Ah, eu não gosto de voltar, eu nunca tenho vontade de voltar, mas depois me acomodo. É engraçado, eu não tenho vontade de voltar, a não ser como eu disse, três semanas, a roupa tá toda suja, tu já estás cansada, é um ritmo muito acelerado, aí tu queres voltar para descansar[...] às vezes eu comentava isso com a minha mãe, ela ficava chateada, mas eu nunca quero voltar (Entrevistada 20/66 anos).

A emoção que mais se mostrou presente no depoimento dos entrevistados ao final das viagens foi a saudade. Esse tipo de emoção provoca uma sensação positiva e faz com que se tenha vontade de reviver momentos e de viajar novamente para determinado local. Assim, ela contribui fortemente para o desejo de repetir a viagem e para uma nova busca de serviços de turismo, dentro das possibilidades físicas e materiais dos consumidores.

[...] e depois tem as recordações. Aí tu vê as fotografias, dá uma saudade. E engraçado que tu vês as fotografias, tu lembras direitinho do que tu fez. [...] aí continua a emoção. Vontade de ir de novo, dá vontade de ir outra vez. [...] gostaria até de ir outra vez, mas agora não tenho mais condições físicas, mas que dá vontade de voltar, dá. (Entrevistada 6/77 anos) 


\subsection{Photo Elicitation Technique}

Para a realização deste trabalho, a PET mostrou-se uma técnica de grande relevância, visto que possibilitou, através do estímulo das fotografias, o acesso a conteúdos emocionais que somente por meio de entrevistas em profundidade não seriam expressos. Muitas vezes, as pessoas, quando solicitadas na primeira etapa da entrevista, não se recordavam de emoções sentidas ou de situações vividas em algumas viagens; todavia as lembranças retornavam na medida em que eram apresentadas as imagens selecionadas por elas e pela entrevistadora. Para Harper (2002), técnicas de pesquisa que utilizam fotografias como forma de suscitar pensamentos são capazes de alcançar partes diferentes e mais profundas da consciência humana, quando comparadas a metodologias puramente verbais. Dessa forma, quando se permite que um consumidor revele seus pensamentos através de um meio de natureza não verbal, é possível aproximar-se mais do significado e da ideia original.

A PET não apenas proporciona mais informações do que as entrevistas puramente verbais, como também propicia acesso a informações diferentes (SAMUELS, 2004). Por exemplo, no contexto de pesquisas de marketing, pedir a potenciais consumidores para lembrarem as suas atitudes ou crenças acerca da utilização de um produto, sem nenhum estímulo visual, é muito diferente do que lhes mostrar uma imagem de um cenário com o produto em uso. Isto ocorre porque existe uma diferença entre "memória" e "visão" (MAGNINI, 2006), a qual foi identificada nas entrevistas realizadas, pois as imagens apresentadas faziam com que as pessoas recordassem de momentos vividos e emoções sentidas semelhantes às apresentadas nas imagens. Isso trouxe grande contribuição para a pesquisa e possibilitou a melhor compreensão das emoções envolvidas no processo de decisão de compra.

A seguir, são apresentados alguns trechos de entrevistas que mostram as emoções dos idosos entrevistados ao recordarem, através da exibição destas imagens, e relatarem suas experiências. As fotos referentes a estes trechos encontram-se na Figura 2.
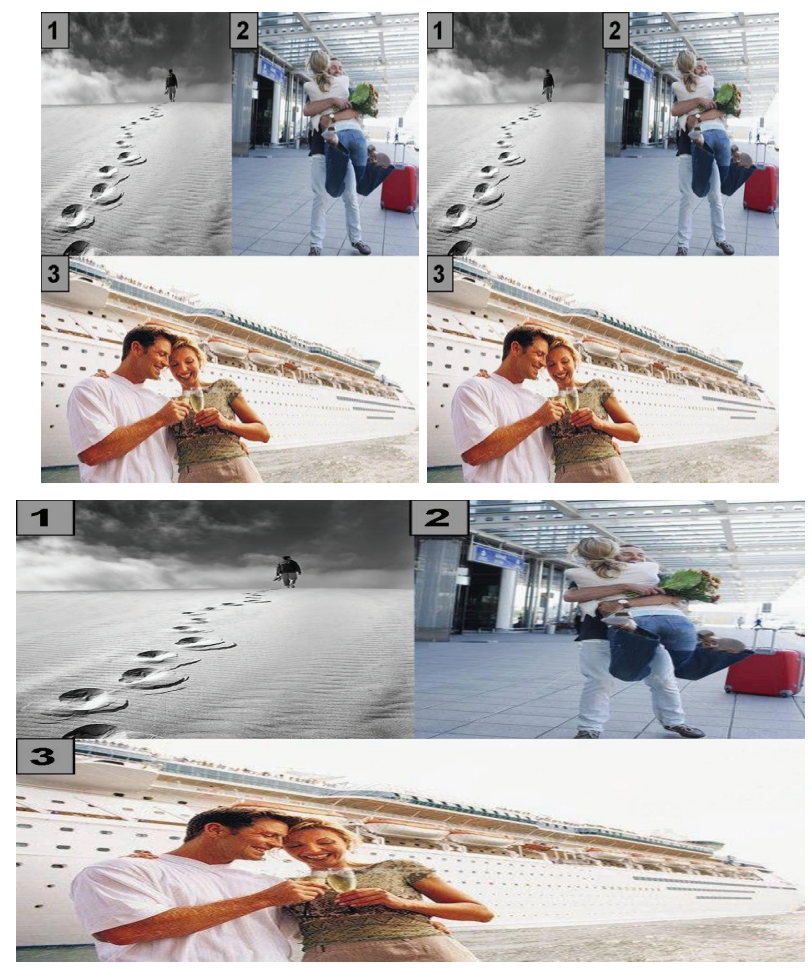

Figura 2: Algumas fotos utilizadas durante a Photo Elicitation Technique. Fonte: Elaborada pelos autores. 
Trecho referente à imagem 1:

Aqui eu me lembrei do deserto, que coisa gostosa! O deserto é um lugar tão bonito, apesar, parece, assim, todo mundo pensa deserto, uma coisa inóspita, mas eu achei que andar no deserto me deu uma sensação de liberdade assim, de imensidão (Entrevistada $6 / 77$ anos).

Trecho referente à imagem 2:

Esta aqui é a emoção na volta de encontrar a família, de reencontrar todo mundo, depois de tanto tempo lá e o medo que eu passei antes de ir, essa emoção foi muito boa! (Entrevistada 13/75 anos).

Trecho referente à imagem 3:

Eles estão brindando uma viagem de navio que eu gostei muito de fazer. Me deixou muita saudade. Meu filho tinha uns dez anos, doze e ele gostou tanto de viajar de navio que ele está sempre querendo voltar [...] Foi muito boa a viagem de navio! (Entrevistada 14/65 anos).

A análise dos depoimentos obtidos nesta etapa mostrou-se de grande valia para a meIhor compreensão dos dados obtidos nas entrevistas como um todo. Klitzing (2004) e Clark-Ibáñez (2004) relatam que resultados positivos obtidos por meio da PET também devem-se ao ambiente informal em que estão inseridos o entrevistador e o entrevistado, criado por intermédio das fotografias. No contexto do presente artigo, devido ao tema em questão ser bastante pessoal, esta aproximação através das imagens tornou-se relevante para o maior aprofundamento das emoções envolvidas nas escolhas de destinos de viagens, conforme os objetivos propostos. Sendo assim, com a utilização da técnica de PET, as emoções puderam ser mais facilmente acessadas e expressas pelos entrevistados.

\section{CONSIDERAÇÕES FINAIS}

Holbrook e Hirschman (1982) ressaltam que compreender os sentimentos e as motivações que surgem no comportamento de compra e entendê-los como um processo cognitivo-afetivo é a chave para aprofundar a compreensão sobre o tema. Entretanto, conforme apresentado anteriormente, ainda há poucos trabalhos realizados sobre emoções utilizando a abordagem qualitativa. Visando contribuir para o preenchimento desta lacuna, este estudo teve como objetivo analisar as emoções presentes no ato de escolha de destinos de viagens pela terceira idade e a sua influência em decisões de compras futuras. Tendo em vista que a população da terceira idade está crescendo em número e importância no país, torna-se relevante compreender como as emoções influenciam no processo de tomada de decisão destas pessoas. Considerando o mercado específico no qual este estudo se inseriu, o gerenciamento do turismo para os consumidores de terceira idade não será eficaz sem uma compreensão da forma pela qual estes tomam decisões e agem em relação ao consumo de produtos turísticos - argumento a que dão suporte Schein et al. (2009). Neste sentido, o presente trabalho possibilitou identificar a presença e a importância das emoções vivenciadas no decorrer de um processo de escolha de destino de viagem e evidenciar que estas emoções são fundamentais para a tomada de decisão de futuras viagens.

Em grande parte dos depoimentos, pode-se verificar que as viagens foram associadas a emoções positivas, pois representam, muitas vezes, a realização de sonhos; motivo pelo qual este 
tipo de emoção acaba se mostrando mais presente do que as emoções negativas - que, em algumas ocasiões, são até esquecidas. Estas últimas acabam sendo associadas basicamente a eventos negativos ocorridos em alguma situação de viagem e a expectativas que não corresponderam com a realidade do local visitado.

A partir da análise das entrevistas, foi possível perceber que as emoções afetam positiva ou negativamente a escolha do destino de viagem, uma vez que experiências e sensações vividas durante viagens anteriores ficam guardadas na memória destas pessoas e têm forte influência sobre o seu processo futuro de decisão. Estas constatações corroboram a ideia de que não há como separar as emoções dos processos cognitivos em quaisquer que sejam os processos de compra vivenciados (ARRUDA, 2002; SCHIFFMAN; KANUK, 2000).

Diferentes emoções mostraram-se presentes antes, durante e depois da ocorrência de uma viagem. Neste sentido, a presença delas nos distintos momentos do processo de consumo influencia um futuro processo de tomada de decisão, e a identificação delas em um processo anterior pode auxiliar nesta compreensão. Entretanto a literatura sobre emoções no comportamento do consumidor geralmente considera as emoções apenas durante o momento da decisão de compra, como pode ser verificado, por exemplo, em Richins (1997) e em Westbrook e Oliver (1991).

Desse modo, este trabalho traz contribuições interessantes para futuras pesquisas, uma vez que, para uma análise mais completa sobre as emoções e a sua influência, separou-as em três etapas: antes, durante e depois da viagem. Esta divisão demonstrou ser favorável ao melhor entendimento das emoções em todo o processo. Este é um ponto que abre caminhos para outros trabalhos, nos quais as emoções podem ser inseridas em modelos de análises estatísticas, buscando-se compreender a sua influência sobre os diferentes momentos do processo de decisão, podendo-se, assim, avaliar seu impacto em escolhas futuras.

As descobertas provenientes da comunidade acadêmica sobre as variáveis emocionais envolvidas no contexto de consumo estão despertando, também, maior atenção por parte dos gestores empresariais, uma vez que estes passaram a perceber a sua utilidade para a formulação de estratégias de venda e fidelização e conquista de novos clientes. Por exemplo, a partir da identificação de quais emoções podem estar associadas às diferentes fases de consumo de um serviço - especialmente nos de longa duração e contato estendido com o cliente, como o turismo --, os profissionais de marketing podem estabelecer ações para melhor gerenciá-las, buscando estimular emoções positivas que resultarão em maior satisfação e desejo de novos atos de consumo (no caso, novas viagens).

Tendo em vista o caráter qualitativo desta pesquisa, sua primeira limitação centra-se na impossibilidade de generalização dos resultados obtidos. Outro fator limitante é que, algumas vezes, as viagens narradas pelos entrevistados foram realizadas há muito tempo e, devido a isso, alguns aspectos emocionais podem não ser lembrados com muita facilidade, razão pela qual é possível que se percam aspectos que seriam muito interessantes de serem analisados.

Para futuras pesquisas envolvendo o tema emoções sugere-se a utilização da videografia para análise e apresentação dos dados. Este tipo de método vem ganhando importância na área de comportamento do consumidor e tem apresentado resultados muito expressivos, sendo muito indicado para análises visuais.

Embora sejam objeto da curiosidade humana há séculos, as emoções ainda não foram totalmente desvendadas e, por essa razão, continuam sendo um tema instigante para as áreas do conhecimento que buscam analisá-las e compreendê-las. O marketing, mais especificamente no campo do comportamento do consumidor, não tem se poupado deste desafio e tem aberto, principalmente na última década, espaços para a realização de pesquisas que contemplem a inclusão das emoções nos seus objetivos de investigação. 


\section{REFERÊNCIAS}

ARRUDA, A. L. Avaliação da Aplicabilidade da Escala Consumption Emotions Set para Mensuração das Emoções em Experiências de Consumo na Cidade de Porto Alegre. 2002. Dissertação (Mestrado em Administração), Programa de Pós-Graduação em Administração, UFRGS, Porto Alegre, 2002.

AZEVEDO, M. S.; MARTINS, C. B.; NÁDIA, P. K.; FARAH, O. E. Segmentação no setor turístico: o turista LGBT de São Paulo. Revista de Administração da UFSM, Santa Maria, v. 5, n. 3, set./dez, 2012. p. 493-506.

BAGOZZI, R. P.; GOPINATH, M.; NYER, P. U. The Role of Emotions in Marketing. Journal of the Academy of Marketing Science, v. 27, n. 2, 1999. p. 184-206.

BALLSTAEDT, A. L. M. P. Comportamento e Estilo de Vida da População Idosa e seu Poder de Consumo. In: II ENCUENTRO LATINOAMERICANO DE DISEÑO. Anais... Universidad de Palermo, Buenos Aires, 2007.

BARDIN, L. Análise de conteúdo. 3a ed. Lisboa: Edições 70, 2008.

BARTOS, R. Over 49: the invisible consumer market. Harvard Business Review, v. 58, n. 1, 1980. p. $140-148$.

BERQUO, E.; CAVENAGHI, S. (2006). Fecundidade em declínio: breve nota sobre a redução no número médio de filhos por mulher no Brasil. Novos estudos - CEBRAP, $n$. 74, 2006. p.11-15.

CLARK-IBÁÑEZ, M. Framing the social world with photo-elicitation interviews. American Behavioral Scientist, v. 47, n. 12, 2004. p. 1507-1527.

COSTA, A. C. R.; FARIAS, S. A. Emoções e Satisfação em compras on-line: $O$ 'ser' é humano em ambientes intermediados por computadores. In: ENANPAD, 28, 2004,
Curitiba. Anais... Curitiba: ANPAD, 2004.

DAMÁSIO, A. Descartes' Error: Emotion, Reason, and the Human Brain. New York: Avon Books, 1994.

The Feeling of what happens: Body and Emotion in the Marketing of Consciousness. Orlando, FL: Harcourt Brace, 1999.

ESPINOZA, F. S.; NIQUE, W. M. Experiências Emocionais em Situações de Consumo de Produtos: Evidências e Proposições de Pesquisa. In: ENANPAD, 27, 2003, Atibaia. Anais... Atibaia: ANPAD, 2003.

ESPINOZA, F. S. O Impacto de Experiências Emocionais na Atitude e Intenção de Comportamento do Consumidor. 2004. Dissertação (Mestrado em Administração). Programa de Pós-Graduação em Administração, UFRGS, Porto Alegre, 2004.

EXAME. O Novo Consumidor Brasileiro. São Paulo: Ed. Abril, n. 916, 1 abr. 2008.

ESTEVES, P.; SLONGO, L. A. O Crescimento da Terceira Idade: Necessidade de Adaptações no Mercado. SEMEAD, 12, 2009, São Paulo. Anais... São Paulo: FEA/USP, 2009.

FARIAS, S.; SANTOS, R. Atributos de satisfação nos serviços de hotelaria: uma perspectiva no segmento da terceira idade. In: ENANPAD, 22, 1998, Foz do Iguaçu. Anais... Foz do Iguaçu: ANPAD, 1998.

FLEISCHER, A.; SEILER, E. Determinants of vacation travel among Israeli seniors: theory and evidence. Applied Economics, v. 34, 2002. p. 421-430.

FLICK, U. Uma Introdução à Pesquisa Qualitativa. 2a ed. Porto Alegre: Bookman, 2004.

FOXALL, G. R. Foundations of consumer behaviour analysis. Marketing Theory, v.1, n.2, 2001. p. 165199.

GODOY, A. S. Pesquisa qualitativa: tipos 
fundamentais. Revista de Administração de Empresas, v. 35, n. 3, 1995.

GOEBERT, B. O Consumidor e os focus groups. HSM Management, São Paulo: HSM, n. 37, mar/abr, 2003. p. 60-63.

GOLDMAN, A.; MCDONALD, S. The Group Depth Interview: Principle and Practice. New Jersey: Prentice Hall, 1987.

GOMES, J. R. S.; SCHUCH JÚNIOR, V. F.; KNEIPP, J. M.; ROSA, L. A. B.; BICHUETI, R. S. Satisfação dos serviços: uma análise da percepção dos clientes do Banco do Brasil. Revista de Administração da UFSM, Santa Maria, v. 5, n. 1, jan/abr, 2012. p. 126-144.

HARPER, D. Talking about pictures: A case for photo elicitation. Visual Studies, v. 17 n. 1, 2002, p. 13-26.

HIRSCHMANN, E.; HOLBROOK, M. Postmodern Consumer Research. Newbury Park: Sage Publications, 1992.

HOLBROOK, M. B.; HIRSCHMAN, E. C. The Experimental Aspects of Consumption: Consumer Fantasies, Feeling and Fun. Journal of Consumer Research, v. 9, n. 2, 1982. p. 132 -140 .

HSIEN, H. W.; CÔNSOLI, M. A.; GIULIANI, A. C. Aspectos sobre a decisão de canais no pequeno varejo: a escolha entre o atacado e o atacarejo. Revista de Administração da UFSM, Santa Maria, v. 4, n. 1, jan./abr, 2011. p. 91-104.

INSTITUTO BRASILEIRO DE GEOGRAFIA E ESTATÍSTICA. Síntese de Indicadores Sociais: Uma análise das condições de vida da população brasileira 2008. Rio de Janeiro, 2008.

IZARD, C. E. Human Emotions. New York: Plenum Press, 1977.

KEMP, E.; KOOP, S. W. Emotion regulation consumption: When feeling better is the aim. Journal of Consumer Behaviour, v. 10, 2011. p. 1-7.

KEMP, E.; BUI, M.; CHAPA, S. The role of advertising in consumer emotion management. International Journal of Advertising, v. 31, $\mathrm{n}$. 2, 2012. p. 339-353.

KINSELLA, K; VELKOFF, V.A. US Census Bureau, Series P95/01-1, An Aging World: 2001. Washington, DC: US Government Printing Office, 2001. Disponível em: <http://www. census.gov/prod/2001>. Acesso em: 22 ago. 2012.

KLITZING, S. W. Women living in homeless shelters: Stress, coping and leisure. Journal of Leisure Research, v. 36, n. 4, 2004. p. 483-512.

KOENIGSBERG, P. The gray wave. Direct Markets, February, 1994. p. 69-71.

KUMAR, A; OLIVER, R. L. Cognitive appraisals, consumer emotions and consumer response. Advances in Consumer Research, v. 24, 1997. p. 17-18.

LADEIRA, R.; GUEDES, E. M.; BRUNI, A. L. Um Estudo do Comportamento do Consumidor Soteropolitano de Terceira Idade em Relação ao Entretenimento e Lazer com Ênfase no Turismo. In: ENANPAD, 27, 2003, Atibaia. Anais... Atibaia: ANPAD, 2003.

LARÁN, J. A. A Influência da Surpresa no Processo Emocional de Formação da Satisfação do Consumidor. 2003. Dissertação (Mestrado em Administração). Programa de Pós-Graduação em Administração, UFRGS, Porto Alegre, 2003.

LAZARUS, R. S. Progress on a Cognitivemotivational-relational Theory of Emotion. American Psychologist, v. 46, n. 8, 1991. p. 819-834.

LEAL, I. J; HAAS, A. N. O significado da dança na terceira idade. Revista Brasileira de Ciências do Envelhecimento Humano, Passo Fundo, jan/jun, 2006. p. 64-71. 
LEE, S.; COMER, L. B.; DUBINSKY, A. J.; SCBAFER, $K$. The Role of Emotion in the Relationship Between Customers and Automobile Salespeople. Journal of Managerial Issues, $v$. 23, n. 2, 2011. p. 206-226.

MAGNINI, V. P. Photo-Elicitation as a Tool to Alleviate International Marketing Mistakes. Journal of Global Competitiveness, v. 14, n. 2, 2006. p. 75-83.

MEHRABIAN, A.; RUSSELL, J. A. An approach to environmental psychology. Cambridge: MIT Press, 1974.

MINAYO, M. C. S. O desafio do conhecimento: pesquisa qualitativa em saúde. 2a ed. São Paulo: Hucitec, 1993.

MOSCHIS, G. Marketing to older adults: an updated overview of present knowledge and practice. Journal of Consumer Marketing, v. 20, n.6, 2003. p. 516-525.

MOWEN, J. C.; MINOR, M. S. Comportamento do Consumidor. São Paulo: Prentice Hall, 2003.

NAM, J; HAMLIN, R; GAM, H; KANG, J; KIM, J; KUMPHAI, P; STARR, C; RICHARDS, L. The fashion-conscious behaviours of mature female consumers. International Journal of Consumer Studies, v. 31, n. 1, 2007. p. 102108.

OLIVER, R. L. Satisfaction: a behavioral perspective on the consumer. New York: McGraw-Hill, 1997.

PETER, J. P.; OLSON, J. C. Understanding consumer behavior. Burr Ridge: Irwin, 1994.

PLUTCHICK, R. A language for the emotions. Psychology Today, Feb, 1980. p. 68-78.

RICHINS, M. L. Measuring Emotions in the Consumption Experience. Journal of Consumer Research, v. 24, n. 2, 1997. p. 127-46.

ROSSI, C. A. V.; HOR-MEYLL, L. F. Explorando Novas Trilhas na Pesquisa do Consumidor. In: ENANPAD, 25, 2001, Campinas. Anais...
Campinas: ANPAD, 2001.

SAMUELS, J. Breaking the ethnographer's frame. American Behavioral Scientist, v. 47, n. 12, 2004. p. 1528-1550.

SCHEIN, M.; PERIN M. G.; SAMPAIO, C. H.; UGALDE, M. M. O Comportamento da Compra de Serviços de Turismo na Terceira Idade. Revista Turismo Visão e Ação - Eletrônica, v. 11, n. 3, set/dez., 2009. p. 341-357.

SCHIFFMAN, L. G.; KANUK, L. L. Comportamento do Consumidor. 6ạ ed. Rio de Janeiro: LTC, 2000.

SHERMAN, E.; SCHIFFMAN, L. G. Quality assessment of older consumers: a retrospective review. Journal of Business and Psychology, v. 6, 1991. p. 107-119.

SHETH, J. N. Comportamento do Consumidor. In: CZINKOTA, M. R. et al. Marketing: as melhores práticas. Porto Alegre: Bookman, 2001. p. 136-167.

SHETH, J.; MITTAL, B.; NEWMAN, B. Comportamento do Cliente: indo além do comportamento do consumidor. São Paulo: Atlas, 2001.

SHIV, B.; FEDORIKHIN, A. Heart and Mind in conflict: the interplay of affect and cognition in consumer decision making. Journal of Consumer Research, v.26, 1999. p. 278-292.

SLONGO, L. A.; ALBRECHT, C. F.; LAVOURAS, D. F.; ESTEVES, P. S.; BARCELOS, R. H. A Moda para a Consumidora da Terceira Idade. In: ENANPAD, 33, 2009, São Paulo. Anais... São Paulo: ANPAD, 2009.

Sternaterg, R. Psicologia Cognitiva. Porto Alegre: Artes Médicas Sul, 2000.

TREVISAN, R. A influência de variáveis emocionais no processo de decisão de compra de automóveis por mulheres. 2004. Dissertação (Mestrado em Administração e Negócios). Faculdade de Administração, 
Contabilidade e Economia, PUCRS, Porto Alegre, 2004.

UGALDE, M. O papel das emoções no processo decisório de compra de imóveis por consumidores da terceira idade. 2006. Dissertação (Mestrado em Administração e Negócios). Faculdade de Administração, Contabilidade e Economia, PUCRS, Porto Alegre, 2006.

WATSON, D.; CLARK, L.A.; TELLEGEN, A. Development and validation of brief measures of positive and negative affect: The PANAS Scales. Journal of Personality and Social Psychology, v.54, jun, 1988. p. 1063-1070.

WESTBROOK, O. R. L.; OLIVER, R. The dimensionality of consumption emotion patterns and consumer satisfaction. Journal of Consumer Research, v. 18, n. 1, 1991. p. 84-91.

ZALTMAN, G. Consumer Researchers: Take a Hike! Journal of Consumer Research, v. 26, mar. 2000. p. 423-428.

Afinal, o Que os Clientes Querem? Rio de Janeiro: Campus, 2003.

ZALTMAN, G. COULTER, R. H. Seeing the voice of the customer: metaphor-based advertising research. Journal of Advertising Research, v. 35, n. 4, jul/aug, 1995. p. 35-51. 